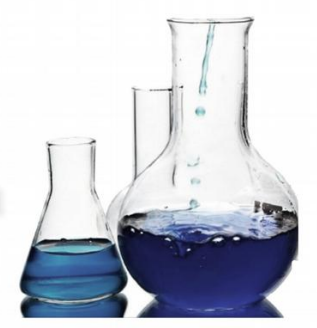

ISSN: 2318-8790

\title{
Editorial 2015 - Especial
}

A área de ensino de Bioquímica integra a reunião Anual da Sociedade Brasileira de Bioquímica e Biologia Molecular (SBBq) desde 1993. Ao longo dos anos, a área foi se estabelecendo e ganhando força e corpo.

A materialização desse trabalho ocorreu com o lançamento, pela SBBq, da Revista de Ensino de Bioquímica e Biologia Molecular (RBEBBM), em 2001. Em 2012 a revista passou por um processo de reestruturação, ampliando seu escopo e equipe de trabalho, passando a se chamar Revista de Ensino de Bioquímica - REB ( Journal of Biochemistry Education).

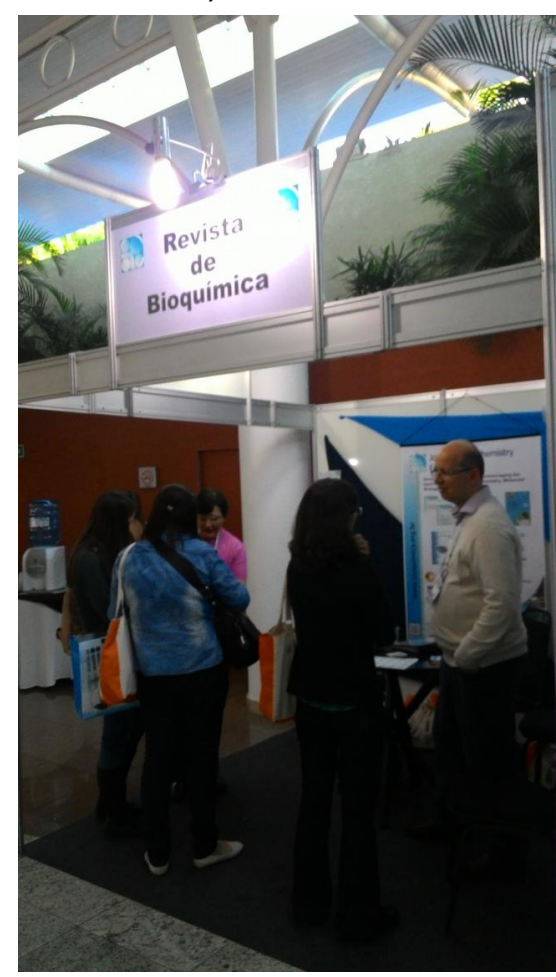

Professores Wagner (UFRJ) e Vera (UFRGS) recebendo visitantes.

Os participantes puderam conversar com parte da equipe da REB, esclarecendo dúvidas, conhecendo novas informações e compartilhando suas experiências, constituindo-se um importante espaço de diálogo sobre Ensino de Bioquímica, Biologia Molecular e áreas correlatas.
Visando ampliar a divulgação da REB, a SBBq proporcionou, desde 2013, um espaço físico (estande) dentro da área do evento, para inserção de banners, materiais publicitários e espaço para contatar e dialogar com os visitantes.

Uma vez que este ano a SBBq sediou a reunião da International Union of Biochemistry and Molecular Biology (IUBMB), o espaço da revista ganhou destaque pela presença de membros do corpo editorial do Brazil, Chile e Uruguai.

O evento ocorreu em Foz do Iguaçu, de 24 a 28 de agosto de 2015 (http://www.sbbq.org.br/iubmb2015). 
Além disso, muitos membros do corpo editorial, por conta da distância física, puderem se conhecer e trocar experiências.

Com relação aos trabalhos apresentados na área de educação, durante o evento, houve dois simpósios, além dos 32 painéis apresentados na área de ensino de Bioquímica (área $\mathrm{K}$ ).

As primeiras apresentações ocorreram no dia 25 de agosto (9:00-11:00), no Simpósio 3 ( Science Education “Leopoldo de Meis"), mediada pelo prof. Dr. Wagner Seixas da Silva (UFRJ, Brasil), com a apresentação três simposiastas, com as seguintes apresentações:

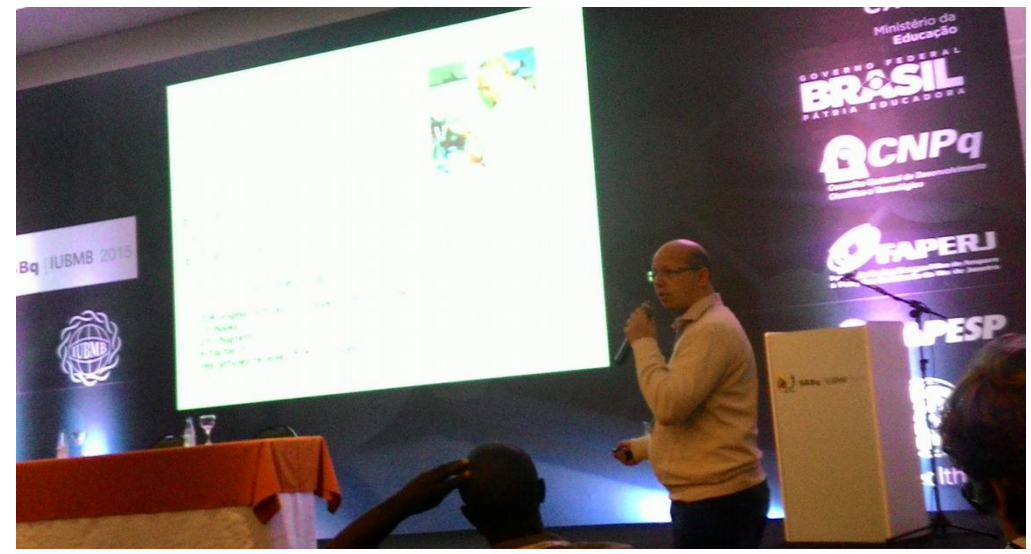

Professor Wagner iniciando as atividades no Simpósio 3 - Science Education "Leopoldo de Meis".

- The Critical Importance of Science Education for Society , por Bruce Albert (University of California - San Francisco, USA);

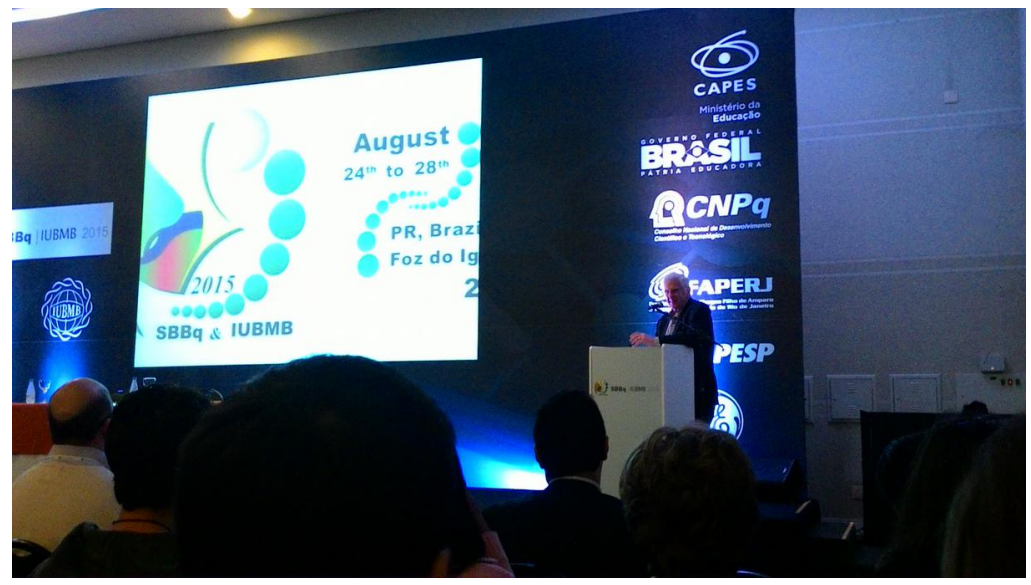

Apresentação do professor Bruce Albert. 


\section{Revista de Ensino de Bioquímica}

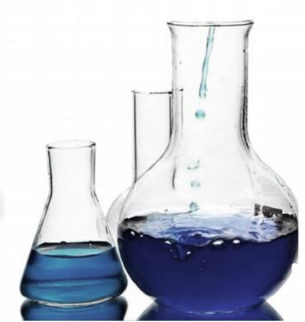

- The Relevance of Neuroscience in Evaluation of Students in Classroom , por Diogo Onofre de Souza (UFRGS, Brasil);

- Replacing Prctical Classes with Experimental Projects , por Paulo S.L. Beirão (UFMG, Brazil).

O segundo simpósio (PABMB: Teaching biochemistry in a connected world) ocorreu no dia 26 de agosto (15:30-17:30), mediada pelo professor Dr. Miguel Castanho (Universidade de Lisboa, Portugal), com a apresentação de quatro simposiastas:

- Hands-on inquiry-based biochemistry courses for improving scientific literacy of school teachers and students, por Andrea T. Da Poian (UFRJ, Brasil);

- Keeping 3D resources in the web to learn on protein structure , por Raual Herrera (Universidad de Talca, Chile);

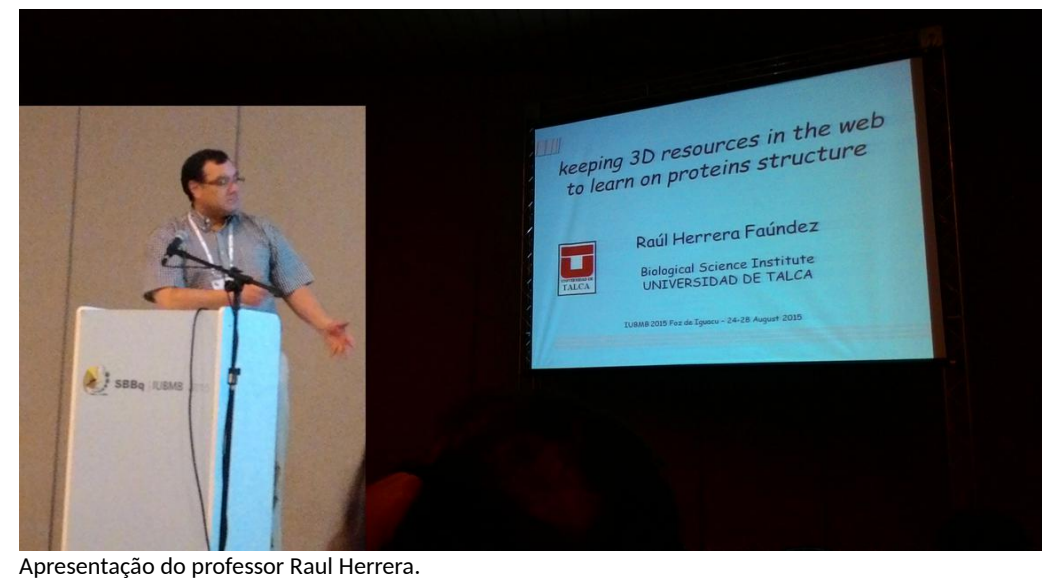

- How Apps-Embedded Assessment can contribute to learning outcomes mapping, por Eduardo Galembeck (Unicamp, Brasil);

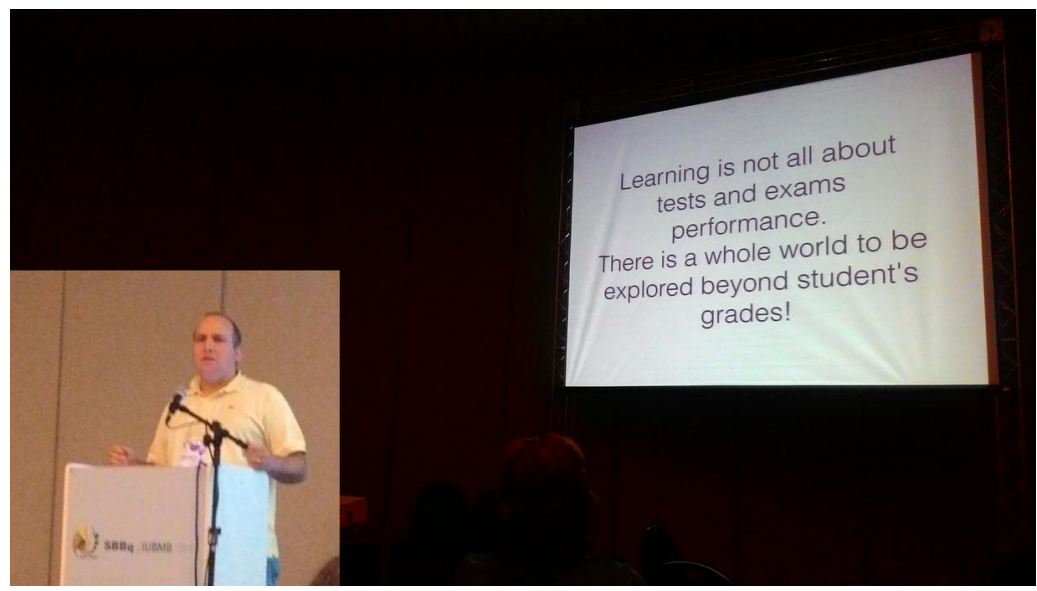

Apresentação do professor Eduardo Galembeck. 


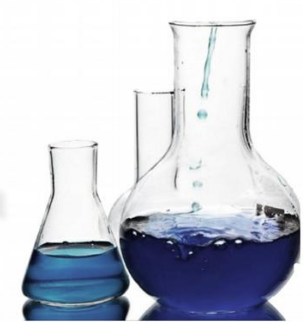

- Using "raw" online data derived from global gene expression experiments for posgraduate teaching activities, por Jose Sotelo (Montevideo, Uruguay).

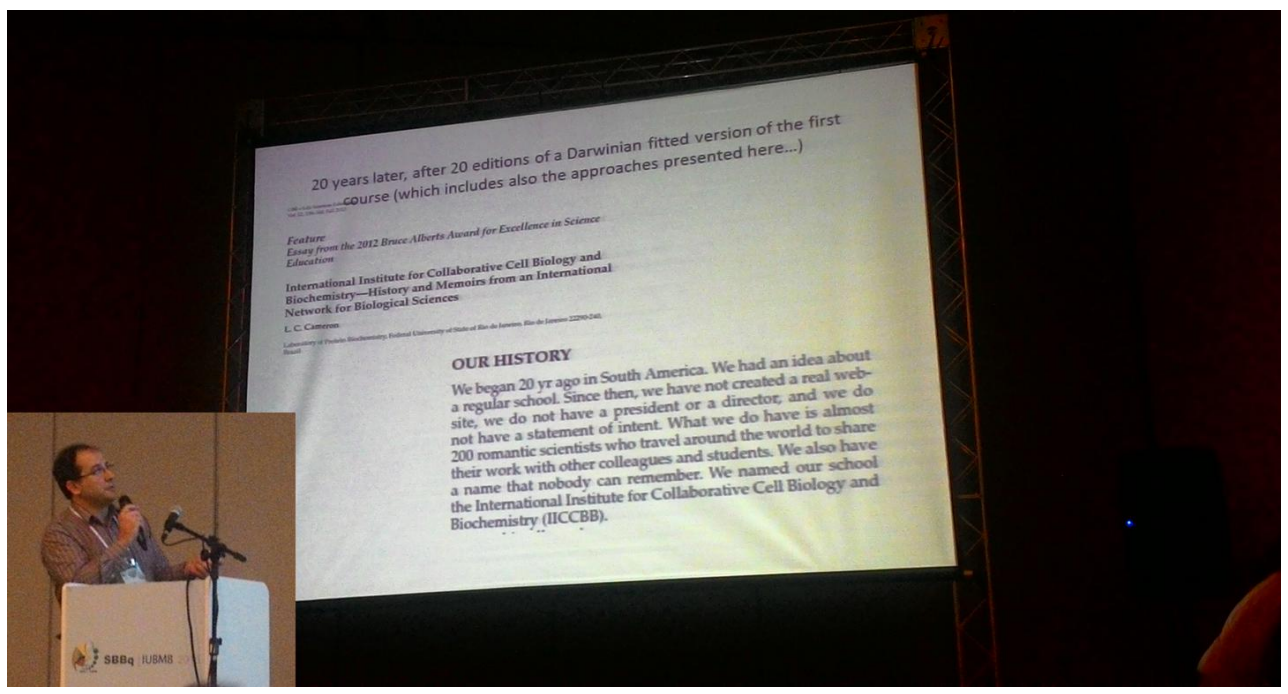

Apresentação do professor Jose Sotelo.

Agradecemos aos membros do corpo editorial e aos colaboradores que estiveram presentes no estande da revista, auxiliando nesse importante processo de valorização do ensino: Aos professores Gabriel Gerber Hornink (Unifal-MG), Eduardo Galembeck (Unicamp), Vera Treis Trindade (UFRGS), Leila Maria Beltramini (UFSCar), Wagner Seixas da Silva (UFRJ), Raul Herrera Faúndez (Universidade de Talca-CH), André Amaral Gonçalves Bianco (Unifesp), Adriana Cassina (Universidade de la República-UR); María Noel Alvarez (Universidade de la República-UR). Aos estudantes Frederico José Moreira Baêta (Unifal-MG), Thanuci Silva (Unicamp), Mayara Lustosa de Oliveira (Unicamp), Caeteno Costa (Unicamp), Caroline Dutra Lacerda (UFRJ).

Atenciosamente

\begin{tabular}{|c|c|c|c|}
\hline ardo B. Torres & $\begin{array}{l}\text { Eduardo Galembeck } \\
\text { Unicamp }\end{array}$ & $\begin{array}{l}\text { Gabriel G. Hornink } \\
\text { Unifal-MG }\end{array}$ & $\begin{array}{l}\text { Vera Maria } \\
\text { UFRGS }\end{array}$ \\
\hline
\end{tabular}

